ERJ

Engineering Research Journal Faculty of Engineering Minoufiya University

\title{
INVESTIGATION OF DIESEL ENGINES PERFORMANCE USING BLENDS OF WASTE VEGETABLE OILS
}

\author{
A. H. Elaskary, S. A. Wilson, H. M. Shabana and M. S. Farag \\ Mechanical Power Engineering Department \\ Faculty of Engineering, Minoufiya University, Shebin El-Kom, Egypt \\ moh_said079@yahoo.com
}

\begin{abstract}
In the present time, the human is facing two essential problems. These problems are the depletion and the environmental pollution of the fossil oil. Vegetable oils after some chemical treatments may be used as an alternative to solve partially these problems, since these oils are renewable and environmental friendly. Biofuel extracted from vegetable oils is considered as a renewable alternative diesel engine fuel. In this study, an experimental investigation on the performance of a direct injection diesel engine is performed. Five blends of waste palm kernel oil (WPKO) with diesel fuel are used (B5-WPKO, B10-WPKO, B20-WPKO, B30-WPKO and B40-WPKO). Another three blends of waste sunflower oil (WSFO) (B20-WSFO, B30-WSFO and B40-WSFO) with diesel fuel (DF) are employed. Because of the great effect of the fuel viscosity on atomization process and combustion, the WPKO and WSFO are preheated to approach diesel fuel viscosity. For this purpose the effect of temperature on the viscosity of WPKO and WSFO is addressed. The study proves that, using fuel blends (B5-WPKO, B10-WPKO and B20-WPKO) these leads to an increase in the brake thermal efficiency (BTE) and decrease in brake specific fuel consumption (BSFC) compared with that of DF at different loads. B30-WSFO blend contributes to increase the BTE compared with that of DF and no significant change is noticed in BSFC. When heating blends, the BTE increase and BSFC decrease compared with that at normal conditions. Waste vegetable oils (WVO) blends can be used in diesel engines without any modification. Mathematical model is developed to simulate the engine behavior when running with WSFO as biofuel. The model is used as a tool to predict the engine performance at wide range of fuel blends. The result show fair agreement with experimental data
\end{abstract}

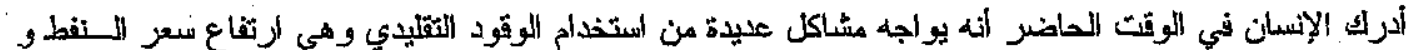

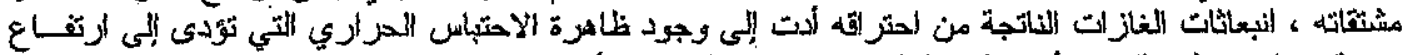

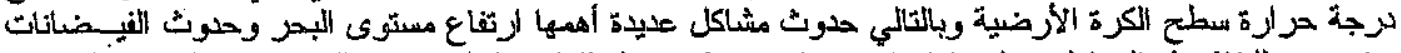

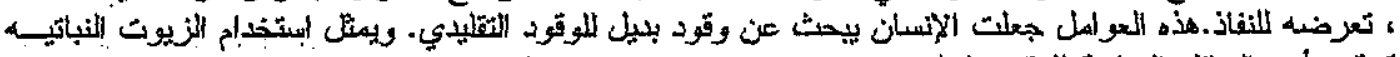

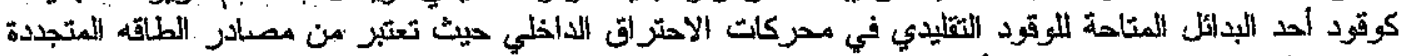

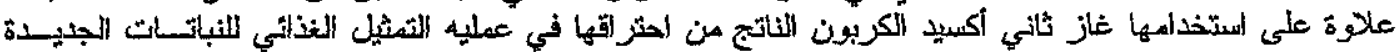

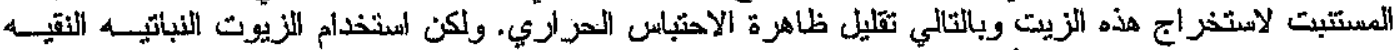

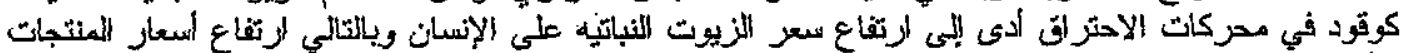

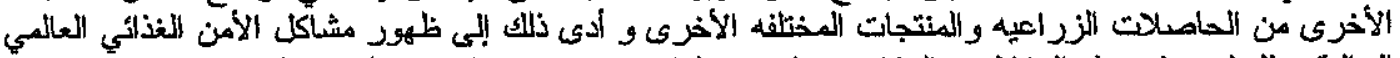

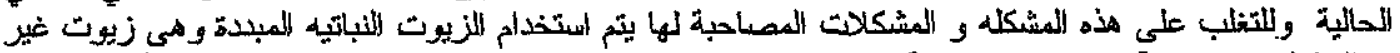

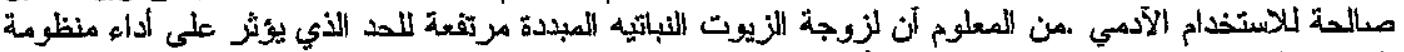

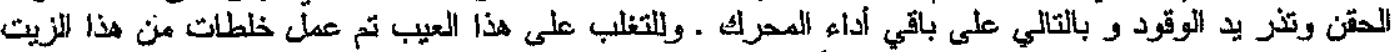

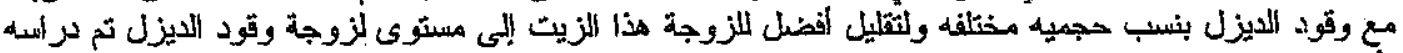

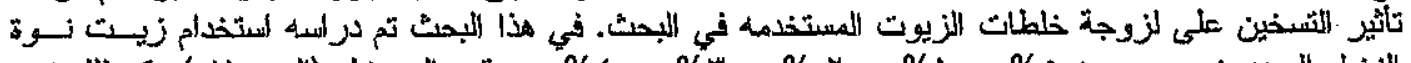

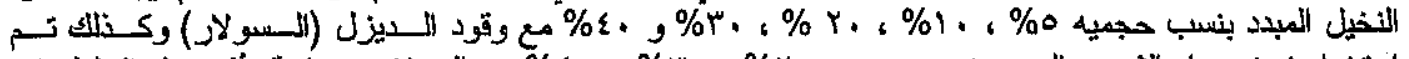

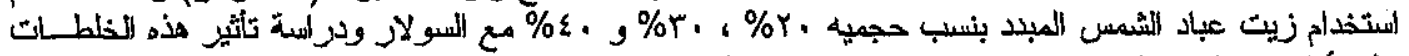

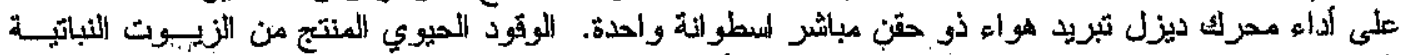

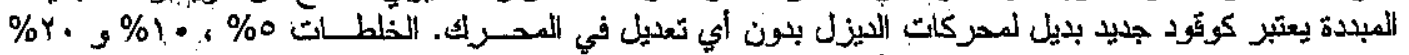

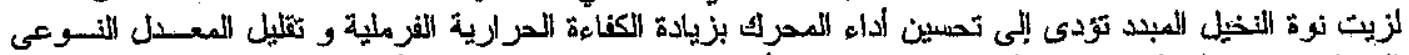

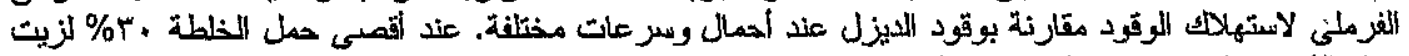

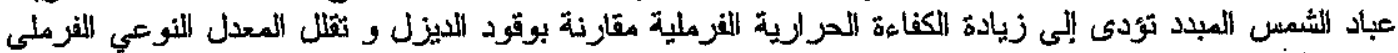

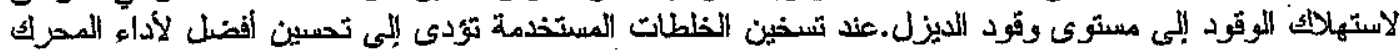




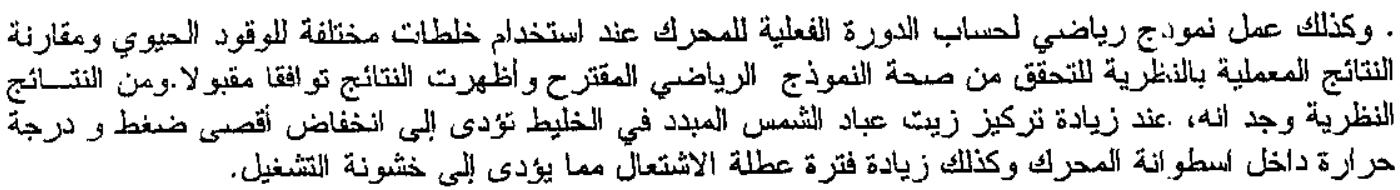

Keywords: Diesel engine, Performance, Diesel fuel, Waste vegetable oils.

\section{INTRODUCTION}

The world's oil reserves are getting used up and their exploitation is getting more and more expensive. One possible way to substitute conventional fuels is to produce so-called biofuels using agricultural feedstock. The two most important biofuels are biodiesel and ethanol. The life-cycle assessment of biodiesel and ethanol has proved that their impact on the environment during the entire life-cycle is much more favorable than those of the conventional fuels (diesel, gasoline), provided the agricultural, climate conditions are advantageous. Beyond environmental benefits, an appropriate biofuel policy is able to capitalize on the economic benefits of biofuels such as the reduction of agricultural surplus stock, the mitigation of unemployment and the dependency on imported oil, rural development, and sustainable agriculture...etc[1].

The idea of using vegetable oils as a fuel for diesel engines is not new. In 1900, Rudolph Diesel used peanut oil to fuel one of his engines at Paris Exposition [2].

Many studies used WVO as biofuels for Diesel engines are carried out. They have found that, WVO can be substituted of conventional diesel fuel for compression ignition engine. But a major disadvantage of WVO is their inherent high viscosity. Modern diesel engines have fuel-injection systems that are sensitive to viscosity changes. High viscosity may lead to poor atomization of the fuel, incomplete combustion, coking of the fuel injectors, ring carbonization, and accumulation of fuel in the lubricating oils. A way to avoid these problems is to reduce the viscosity of vegetable oil in order to improve its performance. There are some methods to reduce the viscosity of vegetable oil. Fuel blending is one of these methods. It has the advantages of improving the use of vegetable oil fuel with minimal fuel processing and engine modification [3].

Many investigators studied the effect of using biofuel on performance of diesel engine. They used different vegetable oil sources, sunflower methyl ester [4], frying sunflower oil $[5]$, sunflower oil $[6,7]$, shale oil [8], jatropha oil [9], rubber seed oil methyl ester [10] ,rapeseed oil [11] and rubber seed oil [12].Differences in results were observed because of some reasons, such as using of different biofuels and pure diesel fuel in each investigation.
The objective of this study is to carry out experimental and theoretical investigations into the performance of diesel engino fuelled with WPKO and WSFO blends compared to those of diesel fuel. The specific objectives of the present investigation are:

* To find the effect of temperature on the viscosity of WSFO and WPKO.

* To evaluate the performance of diesel engine at normal conditions at different engine speeds and loads.

* To evaluate the performarce of diesel engine at constant engine speed, constant load and constant temperature of the injected tuel.

* To compare the experimental results of WPKO blends, WSFO blends, and DF.

* To compare the results of theoretical approach with that of experimental results of WSFO blended with DF.

\section{EXPERMUENTAL SET-UP AND TEST PROCEDURE}

An air cooled, single cylinder, four stroke, DEUTZ F1L511, direct injection diesel engine has been employed as a test engine in the present study. The engine has $100 \mathrm{~mm}$ bore, $105 \mathrm{~mm}$ stroke, compressior ratio of 17 and a rated brake power of $5.7 \mathrm{~kW}$ at $1500 \mathrm{rpm}$. Fuel injection starts at $24^{\circ}$ before TDC. A schematic laysut of the experimental set up is shown in Fig. 1. A simple mechanism has been attached to the engine rack to allow fine variation of the engine speed by controlling the rack position.

An electrical dynamometer with maximum electric power output of $15 \mathrm{HP}$ has been directly coupled to the engine output shaft. The engine is said to be operated at a certain load (percentage of the maximum torque) when the excitation field voltage (applied on the electrical dynamometer) is adjusted to produce a specified engine output power. The values of the excitation field voltage corresponding to the prescribed engine load have been maintained constant over the entire engine speed range during test. The optical tachometer, s used to measure the engine speed. It can measure the engine speed up to $10000 \mathrm{rpm}$ with $\pm 0.01 \%$ accuracy. The pressure drop through the calibrated orifice is measured using a U-tube manometer with $\pm 1 \%$ accuracy to evaluate the air flow rate. Fuel flow races have been achieved 
by using a normal device with different capacities $(100,50 \mathrm{ml}), 1 \mathrm{ml}$ division and stop watch of $1 \mathrm{~s}$ accuracy.

The plan which designed for the experimental investigation is to use five kinds of blends (by volume) of WPKO with DF. i.e. blends of $5 \%$ WPKO with $95 \% \mathrm{DF}$ (B5-WPKO), $10 \%$ WPKO with $90 \% \mathrm{DF}$ (B10-WPKO), 20\%WPKO with 80\%DF (B20WPKO), 30\%WPKO with 70\%DF (B30-WPKO) and $40 \%$ WPKO with $60 \% \mathrm{DF}$ (B40-WPKO) are compared with DF. Three of blends (by volume) of WSFO with diesel fuel (DF) were tested. i.e. blends of $20 \%$ WSFO with $80 \% \mathrm{DF}$ (B20-WSFO), $30 \%$ WSFO with $70 \% \mathrm{DF}$ (B30-WSFO) and $40 \%$ WSFO with $60 \% \mathrm{DF}$ (B40-WSFO) are compared with DF.

Main properties of the fuel tested are shown in Table 1. As shown in this table, pure diesel has the highest gross calorific value, highest cetane number, lowest viscosity and lowest density. When diesel mixed with WVO to make blends, it is found that the more percentage of WVO in the blends, the higher of the viscosity, higher density, the lower the gross calorific value and lower cetane number. Pure WVO has the lowest gross calorific value, the highest viscosity and density.

Table (1) Fuel properties

\begin{tabular}{|c|c|c|c|c|c|}
\hline Fuel & $\begin{array}{c}\text { Calorific } \\
\text { value } \\
\mathrm{kJ} / \mathrm{kg}\end{array}$ & $\begin{array}{c}\text { Viscosity } \\
\mathrm{mm}^{2} / \mathrm{s} \\
\text { at } 35^{\circ} \mathrm{C}\end{array}$ & $\begin{array}{c}\text { Density } \\
\mathrm{kg} / \mathrm{m}^{3}\end{array}$ & $\begin{array}{c}\text { Cetane } \\
\text { No. }\end{array}$ & $\begin{array}{c}\text { Chemical } \\
\text { formula }\end{array}$ \\
\hline DF & 42,700 & 5 & 780 & 48 & $\begin{array}{c}\mathrm{C}_{10.8} \mathrm{H}_{18.7} \\
{[15]}\end{array}$ \\
\hline Pure WPKO & 37,200 & 69.6 & 835 & 36.5 & \\
\hline Pure WSFO & 37,000 & 67.7 & 845 & 37 & $\begin{array}{c}\mathrm{C}_{57} \mathrm{H}_{103} \mathrm{O}_{6} \\
{[13]}\end{array}$ \\
\hline
\end{tabular}

\section{EXPERMIENTAL RESULTS AND DISCUSION}

\subsection{Effect of Blend Heating Temperature on Viscosity}

Figures 2 and 3 show the effect of temperature on the viscosity of WPKO, WSFO and DF. It can be observed that the viscosity of WPKO and WSFO were reduced rapidly with temperature compared to DF.

Based on the results of figures 2 and 3, the kinematic viscosity of pure WPKO, WSFO and DF may be calculated as a function of temperature $\left({ }^{\circ} \mathrm{C}\right)$ using equations (1,2 and 3$)$ given below.

$$
\begin{gathered}
\dot{v}_{\text {WPKO }}=317.382-14.603 \mathrm{~T}+0.30239 \mathrm{~T}^{2}- \\
2.85708 \mathrm{E}-3 \mathrm{~T}^{3}+9.83377 \mathrm{E}-6 \mathrm{~T}^{4} \\
\mathrm{v}_{\text {WSFO }}=203.946-6.34874 \mathrm{~T}+0.0832268 \mathrm{~T}^{2}- \\
3.76505 \mathrm{E}-4 \mathrm{~T}^{3}-2.90516 \mathrm{E}-7 \mathrm{~T}^{4}
\end{gathered}
$$

$$
\begin{gathered}
V_{\mathrm{DF}}=36.6845-2.04959 \mathrm{~T}+0.0474638 \mathrm{~T}^{2}- \\
4.87519 \mathrm{E}-4 \mathrm{~T}^{3}+1.83263 \mathrm{E}-6 \mathrm{~T}^{4}
\end{gathered}
$$

The kinematic viscosity of any WVO blend can be calculated from equation (4) as follows:

$$
v_{\text {Blend }}=(1-B R)^{*} v_{\mathrm{DF}}+\mathrm{BR} * v_{\mathrm{WvO}}
$$

\subsection{Air - Fuel Ratio}

Figures 4 and 5 show the measured AFR for different WVO blends used at different loads versus engine speeds. At constant speed the quality of air enters to engine cylinder is the same for all fuel used. It can be observed that for WSFO blends, AFR is less than that of DF at all loads. This is due to the combined effect of viscosity and density of these blends and poor volatility. For WPKO blends, it can be observed that AFR is less than that of DF at no load. If the load increases the AFR for BS-WPKO, B10-WPKO and B20-WPKO will be higher than that of DF.

\subsection{Brake Specific Fuel Consumption}

The brake specific fuel consumption is the reciprocal measure of the brake thermal efficiency. So, it used to evaluate the effect of WVO blends on the engine performance. The brake specific fuel consumption is calculated as follows.

$$
B S F C=\frac{\dot{m}_{\text {fuel }}}{B P} \quad \cdot \quad(\mathrm{gm} / \mathrm{kW} \cdot \mathrm{hr})
$$

Calculation of BSFC of diesel engine requires measurements of volume flow rate, density and brake power.

Figures 6 and 7 present experimental results of engine brake specific fuel consumption for used different fuels. The engine BSFC decreased with the increase of engine loads, as shown in Fig. 6. It can be observed that the BSFC for WSFO blends increased compared with that of DF at $20 \%$ and $40 \%$ of load. This may be due to the increase in mechanical efficiency. For B30-WSFO blend no significant change is noticed in BSFC at $60 \%$ of load. Fig. 7 shows the variation of BSFC for the diesel engine using WPKO blends and DF at different loads and engine speeds. It can be observed that the BSFC for B5-WPKO, B10-WPKO and B20-WPKO is less than that of $\mathrm{DF}$ at all loads.

\subsection{Brake Thermal Efficiency}

The brake thermal efficiency of an engine is inversely proportional to its BSFC and the calorific value of the fuel. The brake thermal efficiency is defined as:

$\eta_{t h, b}=\frac{3600}{B S F C * C V}$

Where: $\quad B S F C(\mathrm{Kg} / \mathrm{kW} . \mathrm{hr})$ 
The variation of brake thermal efficiency of the engine with various WSFO/DF blends is shown in Fig. 8 and compared with the BTE obtained with DF. From the test results it was observed that the BTE of the blends (B20-WSFO and B40-WSFO) were lower than that with $\mathrm{DF}$ at all loads. A reasonably good BTE was also observed with the B30-WSFO at maximum load. The drop in the BTE for blends can be attributed to the poor combustion characteristics of the WSFO due to its high viscosity and poor volatility.

Figure 9 compares the BTE of WPKO blends and $\mathrm{DF}$ at different loads with engine speeds. The BTE for all blends at high speeds is higher than that of DF at $20 \%$ of load. The BTE for B10-WPKO and B20WPKO is better than that of DF at $40 \%$ and $60 \%$ of load. These results may be due to that the calorific values of blends are lower than that DF.

\subsection{Effect of Blend Heating Temperature on BSFC and BTE}

The aim of heating the Diesel/biofuel blends is to decrease its viscosities by using relationship between the hot water around HHP and the temperature of exhaust fuel from the injector. The mechanism which used in this measurement is shown in Fig. 10.

Relation between hot water temperature and temperature of Diesel/biofuel blends is shown in Fig.11.

The effect of WVO (WPKO and WSFO) blends preheating on BSFC and BTE have been studied. At room temperature the viscosity of WVO is about 12 times higher than that of DF. To lower WPKO and WSFO viscosity close to that of DF viscosity, the temperature of the WVO blends must be increased to $70^{\circ} \mathrm{C}$ or more.

Figures 12 and 13 show the effect of blend ratio on BSFC and BTE at constant load, constant engine speed and constant fuel injection temperature $(60 \%$ load, $\mathrm{N}=1500 \mathrm{rpm}$ and $\mathrm{T}_{\mathrm{f}}=70{ }^{\circ} \mathrm{C}$ ). It can be observed that the BSFC decreased by $6.5 \%$ and BTE increased by $7.5 \%$ for all blends with heating fuel; because of lower viscosity for all blends due to heating.

\section{MATHEMATICAL MODEL}

The objective of mathematical model is to simulate the actual thermodynamic cycle inside the engine cylinder. The proposed model is used to study the engine performance under different operating conditions and fuel types (different blends of WSFO and DF)

\subsection{Assumptions}

In the present model, the following assumptions were taken into consideration:
1. The cylinder contents is treated as homogeneous mixture and under equilibrium condition. So, the kinetics of chemical reaction rates are not considered.

2. The gas mixture is considered as one dimensional, compressible and time dependant.

3. The heat losses from the cylinder are taken into account.

4. According to the high level of temperature during the combustion and early part of expansion process, the dissociation of $\mathrm{CO} 2$ is considered.

\subsection{Governing Equations}

According to the previously mentioned assumptions, the conservation equations of mass and energy are adopted according to the present assumptions. The model depends on the relation between the kinematics of mechanical parts and the basic conservation equations for the working mixture inside the cylinder. Details of thie proposed model are presented as follows.

\subsubsection{The instantaneous cylinder volume}

From the kinematics of the crank - slider mechanism (shown in Fig.14), the instantaneous piston displacement is calculated as follows:

' $S_{\theta}=\left[L_{\text {con }}+R\right]-\left[R \cdot \cos \theta+\sqrt{L_{c t s}^{2}-(R \cdot \sin \theta)^{2}}\right]$

The corresponding cylinder volume is calculated as follows:

$$
V=\frac{\pi}{4} D^{2} \cdot\left[S_{\theta}+\frac{2 R}{(C R-1)}\right]
$$

\subsubsection{Equation of state}

While the cylinder contents are considered as a perfect gas then,

$$
P V=n R_{U} T
$$

\subsubsection{Energy equation}

The time dependent differential conservation equation of energy representing the compression, combustion and expansion process is written as follows:

$$
\frac{d q}{d t}-p \frac{d V}{d t}=\frac{d E}{d t}
$$

\subsubsection{Conservation of mass}

The mass of cylinder mixture is considered constant during the compression, combustion and expansion process. So during the closed rocess the following equation is corisidered.

$\mathrm{m}_{\mathrm{R}}=\mathrm{m}_{\mathrm{P}}$

\subsection{Combustion Model}

For homogenous mixture, one dimension flow, the single zone model is found to te the suitable model. 
The model employs the equations of chemical reaction at equilibrium condition, fuel burnt and fuel burning rate.

\subsubsection{Equation of chemical reaction}

The equation of chemical reaction for non dissociated combustion is presented. The equation is valid for all hydrocarbon fuels. The mixture of the reactant is lean. This is due to the amount of excess oxygen existing in the reactants, which control the final products. The general form of the chemical reaction is written as follows:

$$
\begin{array}{r}
(1-\mathrm{BR})^{*} \mathrm{C}_{\mathrm{X}} \mathrm{H}_{\mathrm{Y}}+\mathrm{BR}^{*} \mathrm{C}_{\mathrm{n}} \mathrm{H}_{\mathrm{m}} \mathrm{O}_{\mathrm{z}}+\lambda^{*} \mathrm{X}_{\mathrm{th}}\left(\mathrm{O}_{2}+3.76 \mathrm{~N}_{2}\right) \\
\longrightarrow a \mathrm{CO}_{2}+\mathrm{b} \mathrm{H}_{2} \mathrm{O}+\mathrm{d} \mathrm{O}_{2}+\mathrm{e} \mathrm{N}_{2}
\end{array}
$$

\subsubsection{Models for fuel burning rate}

During the combustion process, part of the fresh mixture is burned and transformed into products. The combustion proceeds until all the amount of the fresh charge is burned completely.

Assigning the instantaneous amount of fuel burning rate is essential for combustion model. Watson model [14] is employed in present work.

\subsubsection{Watson model}

Watson suggests that, fuel burning rate depends on the two mode of combustion in diesel engine (premixed \& diffusion). The combustion starts with the pre-mixed mixture prepared during the delay period. The rest of fuel injected later is burned by diffusion process. This can be expressed mathematically as follows:

$$
\begin{aligned}
& \mathrm{FB}=\beta * \mathrm{fl}(\mathrm{t})+(1-\beta)^{*} \mathrm{f} 2(\mathrm{t}) \\
& F B R=\frac{d(F B)}{d t}
\end{aligned}
$$

Where:

$$
\begin{aligned}
& f 1 \cdot(t)=\text { pre-mixed burning function } \\
& f 2(t)=\text { diffusion burning function }
\end{aligned}
$$

The phase proportionality factor $(\beta)$ will largely be a function of ignition delay and can be calculated as follows:

$$
\beta=1-\frac{a \cdot F^{b}}{I D^{c}}
$$

The ignition delay can be calculated from an empirical formula [15] as follows:

$$
\begin{aligned}
& I D(C A)=\left(0.36+0.22 \cdot U_{P}\right) \exp \left[E_{A} \cdot\left(\frac{1}{R_{U} \cdot T}-\frac{1}{17190}\right) \cdot\left(\frac{21.2}{P-12.4}\right)^{0.63}\right] \\
& E_{A}=\frac{618 \cdot, 840}{C N+25}
\end{aligned}
$$

\subsection{Dissociation of Carbon Dioxide}

Due to the high temperature and pressure inside the cylinder during the combustion and expansion process, some of the combustion products are dissociated into another species. In the present work, the dissociation of carbon dioxide to carbon monoxide and oxygen is considered. The reaction equation for this case under equilibrium condition is as follows.

$\mathrm{CO}+\frac{1}{2} \mathrm{O}_{2} \Leftrightarrow \mathrm{CO}$,

Concentrations of $\mathrm{CO}_{2}, \mathrm{CO}$ and $\mathrm{O}_{2}$ are obtained from the following equation:

$K_{P}=\frac{P_{\mathrm{CO}_{2}}}{P_{\mathrm{CO}} \sqrt{P_{\mathrm{O}_{2}}}}$

The equilibrium constant $K_{P}$ is determined from Gibbs function [16] for the considered reactant as follows:

$$
\ln K_{P}=\sum\left(\frac{n_{i} \cdot g(T)}{R_{U} \cdot T}\right)_{R}-\sum\left(\frac{n_{i} \cdot g(T)}{R_{U} \cdot T}\right)_{P}-\frac{\Delta H_{O}}{R_{U} \cdot T}
$$

\subsection{Heat Transfer Model}

Heat losses from the working fluid are mainly due to radiation from flame front and convection from the gases to the cylinder walls. Assuming that the amount of heat transfer by radiation is very low compared with that by convection so', the heat transferred by radiation can be neglected. The convective heat transfer coefficient can be obtained from widely used Woschni model as follows:

\subsubsection{Woschni Model}

Woschni [14] used the dimensionless analysis to obtain the coefficient of heat transfer as follows.

$$
h_{1}=\frac{K_{1} \cdot P^{0.8}}{D^{0.2} \cdot T^{0.53}}\left[K_{2} \cdot U_{p i s}+K_{3} \cdot \frac{V \cdot T_{r f}}{P_{r e f} \cdot T_{r e f}} \cdot\left(P-P_{m}\right)\right]^{0.8}
$$

\subsection{Initial Conditions and Solution Procedures}

The compression stroke is considered to begins at B.D.C. The initial air temperature at the beginning of compression stroke is calculated as follows:

$T_{1}=\frac{T_{o}+\Delta T w+\gamma_{r} \cdot T_{r}}{1+\gamma_{r}}$

The amount of moles inside the cylinder is given by the equation of state as follows:

$$
n_{1}=\frac{P_{c y} \cdot V_{c y}}{R_{y} \cdot T_{c y}}
$$

The total amount of moles is kept constant during the compression stroke at which no chemical reaction is considered. The instantaneous cylinder volume is calculated from previously mentioned crank slider mechanism. The temperature and pressire inside the cylinder is calculated from both the energy equation and the equation of state. These equations are applied on two finite points on the compression process 1 and 2 . While point 1 represents the initial condition, point 
2 is specified according to the next crank angle step as the following procedure:

- Energy equation for closed system.

$$
d Q=d E+d W . D
$$

Solving this equation with the finite difference technique, the following form is obtained.

$$
E_{2}\left(T_{2}\right)-E_{1}\left(T_{1}\right)+\frac{P_{1}+P_{2}}{2} \cdot\left(V_{2}-V \nu\right)-Q_{\text {loss }}=0.0
$$

Where:

$$
\begin{aligned}
& \left.E_{1}\left(T_{1}\right)=n_{i} \cdot \sum_{i=1}^{k} X_{i} \cdot R_{i}\left(\sum_{J=1}^{s} a_{i} \cdot T_{1}^{s}\right]-T_{1}\right)+n_{t} \sum_{i=1}^{k} X_{i} \cdot E_{O}(0) \\
& \left.E_{2}\left(T_{2}\right)=n_{i} \cdot \sum_{i=1}^{z} X_{i} \cdot R_{i}\left(\sum_{J=1}^{s} a_{i} \cdot T_{2}^{\prime}\right]-T_{2}\right)+n_{t} \sum_{i=1}^{z} X_{i} \cdot E_{O}(0)
\end{aligned}
$$

Equation (20) is solved numerically by using one of the predictor - corrector methods [16]. For this purpose the equation is reformed as follows.

$$
F\left(T_{2}\right)=E_{2}\left(T_{2}\right)-E_{1}\left(T_{1}\right)+\frac{P_{1}+P_{2}}{2} \cdot\left(V_{2}-V_{1}\right)-Q_{\text {loss }}
$$

Newton - Raphson method [16] (iteration method) is used to find $\mathrm{P}_{2}, \mathrm{~T}_{2}$ and $\mathrm{Q}_{\text {loss }}$ as follows:

Assume that $\mathrm{T}_{2}=\mathrm{T}_{1}$

$$
P_{2}=\frac{n_{1} \cdot R_{n} \cdot T_{2}}{V_{2}}
$$

Where:

$$
\begin{aligned}
& n_{1}=\frac{P_{1} \cdot V_{1}}{R_{4} \cdot T_{1}} \\
& F\left(T_{2}\right)=E_{2}\left(T_{2}\right)-E_{1}\left(T_{1}\right)+\frac{\frac{n_{1} \cdot R_{u} \cdot T_{2}}{V_{2}}+P_{1}}{2} \cdot\left(V_{2}-V_{1}\right)-Q_{\text {ioss }} \\
& \bar{F}\left(T_{2}\right)=\frac{\partial F\left(T_{2}\right)}{\partial T_{2}} \\
& \bar{T}_{2}=T_{2}-\left(\frac{F\left(T_{2}\right)}{F\left(T_{2}\right)}\right)
\end{aligned}
$$

Check on the assumed value of $\mathrm{T}_{2}$

Error $=\mid\left(\mathrm{T}_{2}\right)$ calculated $-\left(\mathrm{T}_{2}\right)$ assumed $\mid$

$$
\text { i,e. Error }=\left|\bar{T}_{2}-T_{2}\right|
$$

* If Error $\leq$ allowable, the solution is convergent and the required temperature $\left(T_{2}\right)$ and pressure $\left(P_{2}\right)$ is obtained.

Take $T_{1}=T_{2}, P_{1}=P_{2}$ and $V_{1}=V_{2}$ (for the next crank angle degree calculations.)

* If Error > allowable, take $T_{2}=T_{2}^{-}$to recalculate $E_{1}, E_{2}, P_{2}$ and $F\left(T_{2}\right)$ then contimue the iteration procedure until the following condition satisfy (Error $\leq$ allowable).

\section{VALIDATION OF NIATHEMATICAL MODEL}

To verify the mathematical model, predicated results for the brake power are compared with the experimental results. Fig. 15 shows the variation of BP with engine speed for both experimental work and theoretical analysis for all types of fuel (DF and blends of WSFO with DF).

\section{DISCUSSION OF MATHEMATICAL MODEL RESULTS}

The mathematical model presented is used to study the engine behavior under different operating condition and two different fuel types (DF and blends of WSFO with DF). The model is used to examine the engine beyond the experimental data limit and to extend the effect of different factors on the engine performance.

\subsection{Theoretical Results of Diesel Fuel}

\subsubsection{Effect of Ioad on pressure and temperature.}

Figure 16 represent the effect of load on pressure and temperature with crank angle degree. From this figure it was found that, when the load increases, the cylinder maximum pressure and temperature will increase. This is because the concentration of $\mathrm{O}_{2}$ decreases in the products.

6-1-2 Effect of engine speed on pressure and temperature

The engine speed is represented in Fig. 17 from these figures it is found that, at constant of excess air factor $(\lambda=2.5)$, when increasing the engine speed, the cylinder pressure and temperature are decreases.

\subsection{Comparison between theoretical results for DF and WSFO blends.}

\subsubsection{Effect of blend ratio on pressure and temperature.}

Figure 18 represent the effect of blend ratio on pressure and temperature with crank angle degree. From this figure it was found that, when WSFO blend with DF increase, the cylinder maximum pressure and temperature will decrease. This is because of the highest $\mathrm{CO}_{2}$ concentration.

\subsubsection{The ignition delay}

Figure 19 represents the ignition delay for both DF and WSFO blends with DF. The ignition delay increase by increasing of WSFO concentration in the blend. This is because the viscosity of WSFO is higher than DF. The ignition delay can be calculated from equation (13). 


\section{CONCLUSIONS}

An experimental and theoretical investigation of the performance of a diesel engine using $\mathrm{DF}$ and blends of WVO with DF were conduced. The following conclusions were obtained:

1. WVO (WPKO and WSFO) blends as a new biofuel can be used in diesel engines without any engine modification.

2. Using fuel blends (B5-WPKO, B10-WPKO and $\mathrm{B} 20$-WPKO) lead to an increase of BTE and decrease of $\mathrm{BSFC}$ compared with that of DF at different loads.

3. At maximum load, the BSFC for B30-WSFO is lower to the level of DF.

4. At maximum load, B30-WSFO leads to an increase by $4 \%$ of BTE compared with that of DF.

5. In case of blends heating, the BTE increase by $7.5 \%$ and $\mathrm{BSFC}$ decrease by $6.5 \%$ compared with the values of BTE and BSFC without blend heating.

6. The mathematical model gives a good agreement in view of the comparison with theoretical results with deviation of $\pm 0.10 \%$.

7. When the concentration of WSFO increase, the cylinder maximum pressure and temperature will decrease.

8. The ignition delay increase by increasing of WSFO concentration in the blend which lead to rough engine running.

\section{REFERENCES}

[1] Dániel PUPPÁN, "Environmental Evaluation of Biofuels",PERIODICA POLYTECHNICA SER. SOC. MAN. SCI. VOL, 10, PP, 95-116 (2002).

[2] Ayhan Demirbas, "Biodiesel from vegetable oils via transesterification in supercritical methanol", Energy Conversion and Management 43 (2002) 2349-2356.

[3] Y.D.Wang, T.Al-Shemmeri, P.Eames, J.McMullan, N.Hewitt, Y.Huang, S.Rezvani, "An experimental investigation of the performance and gaseous exhaust emissions of a diesel engine using blends of a vegetable oil", Applied Thermal Engineering,vol.,26, pp, 1684-1691 (2006).

[4] Zafer Dulger, Cafer Kaplan, "Utilization of sunflower methyl ester as a diesel engine fuel", SAE TECHNICAL, PAPER SERIES, 2001-013633.

[5] Turgut Özaktaş," Compression ignition engine fuel properties of a used sunflower oil-diesel fuel blends", Energy Source 22 (2000) 377-382.

[6] C.D. Rakopoulos, K.A. Antonopoulos, D.C. Rakopoulos, D.T. Hountalas, E.G.Giakoumis,"
Comparative performance and emissions study of a direct injection diesel engine using blends of diesel fuel with vegetable oils or bio-diesel of various origins", Energy Conversion and Management 47 (2006) 3272-3287.

[7] Turgut Özaktaş," Altemative diesel fuel study on four different types of vegetable oils of Turkish origin", Energy Source 19 (1997) 173-181.

[8] Gvidonas Labeckas, Stasys Slavinskas, "Performance and exhaust emission characteristics of direct-injection diesel engine when operating on shale oil", Energy Conversion and Management 46, (2005) 139-150.

[9]F.K.Forson, E.K.Oduro, E.Hammond-Donkoh, "Performance of jatropha oil blends in a diesel engine", Renewable Energy 29 (2004) 11351145.

[10]A.S.Ramadhas, C.Muraleedharan, S.Jayaraj," performance and emission evaluation of a diesel engine fueled with methyl esters of rubber seed oil", Renewable Energy 30 (2005) 1789-1800.

[11] Gvidonas Labeckas, Stasys Slavinskas, "Performance of direct-injection off-road diesel engine on rapeseed oil", Renewable Energy 31 (2006) 849-863.

[12] A.S. Ramadhas, S.Jayaraj, C.Muraleedharan, "Characterization and effect of using rubber seed oil as fuel in the compression ignition engines", Renewable Energy 30 (2005) 795-803.

[13] Recep Altm, Selim Çetinkaya, Hüseyin Serdar Yücesu, "The potential of using vegetable oil fuels as fuel for diesel engines", Energy Conversion and Management 42 (2001) 529m538.

[14]Watson N. Janota M.S. "Turbocharging the internal combustion engine", Mac-Millan Pub. London, 1984.

[15] John B.Heywood, "Internal combustion engine fundamentals",McGraw-Hill, 1989.

[16] Rowland S. Benson and N.D. Whitehouse, "Internal combustion engines" Pergamon Press. 1979.

\section{NOMENCLATURE}

\section{Symbols}

a, $b$ and $c$ Watson model constants

$C R$ Compression ratio

$\mathrm{CN}$ Cetane number

C.V Calorific value

D Piston diameter

E Internal energy

$\mathrm{E}_{\mathrm{o}} \quad$ Internal energy at zero absolute temperature

$E_{\mathrm{A}} \quad$ Activation energy

F. Equivalence ratio $(=1 / \lambda)$

FB The fuel burnt

FBR Fuel burning rate 


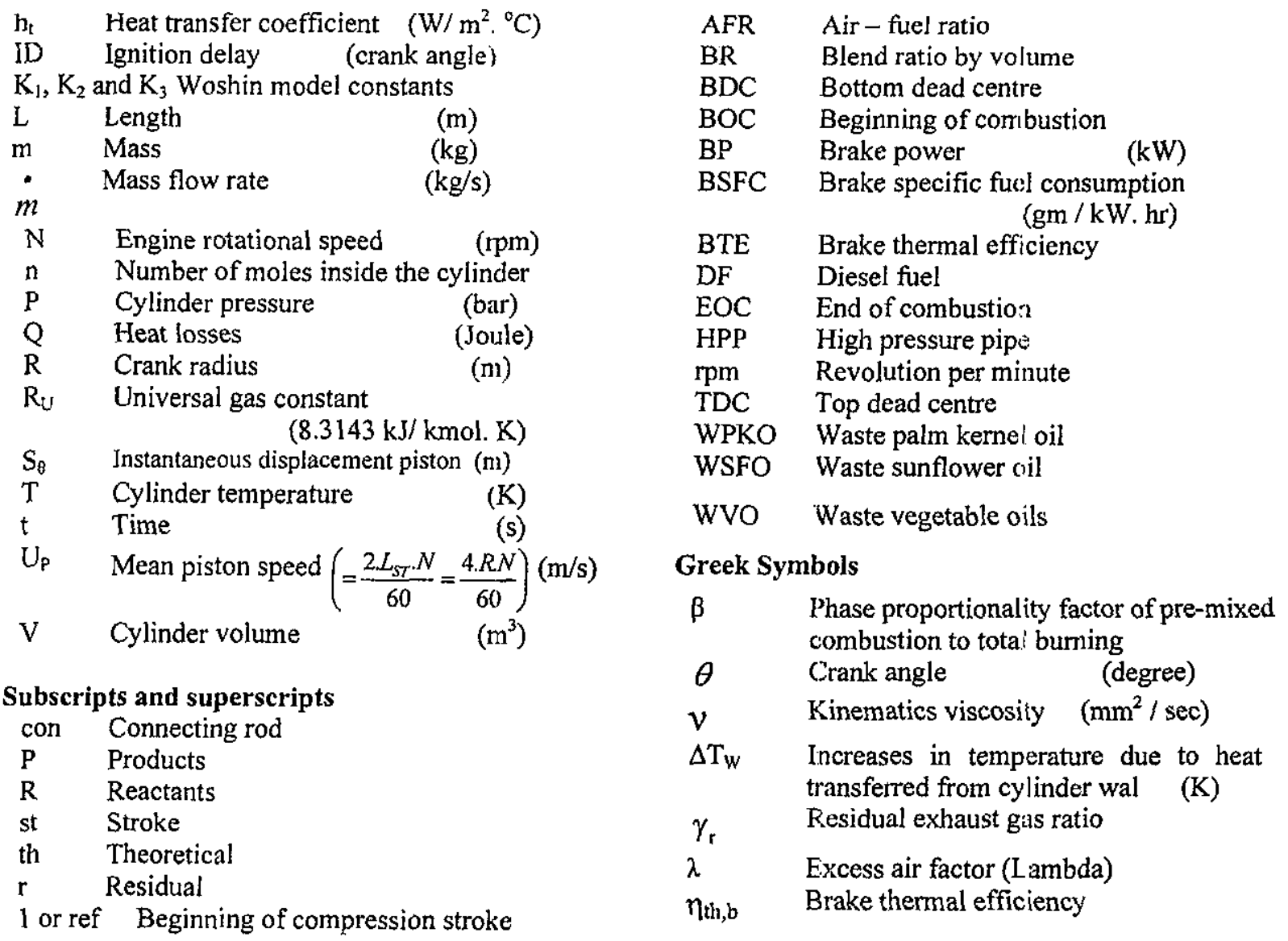

\section{Abbreviations}

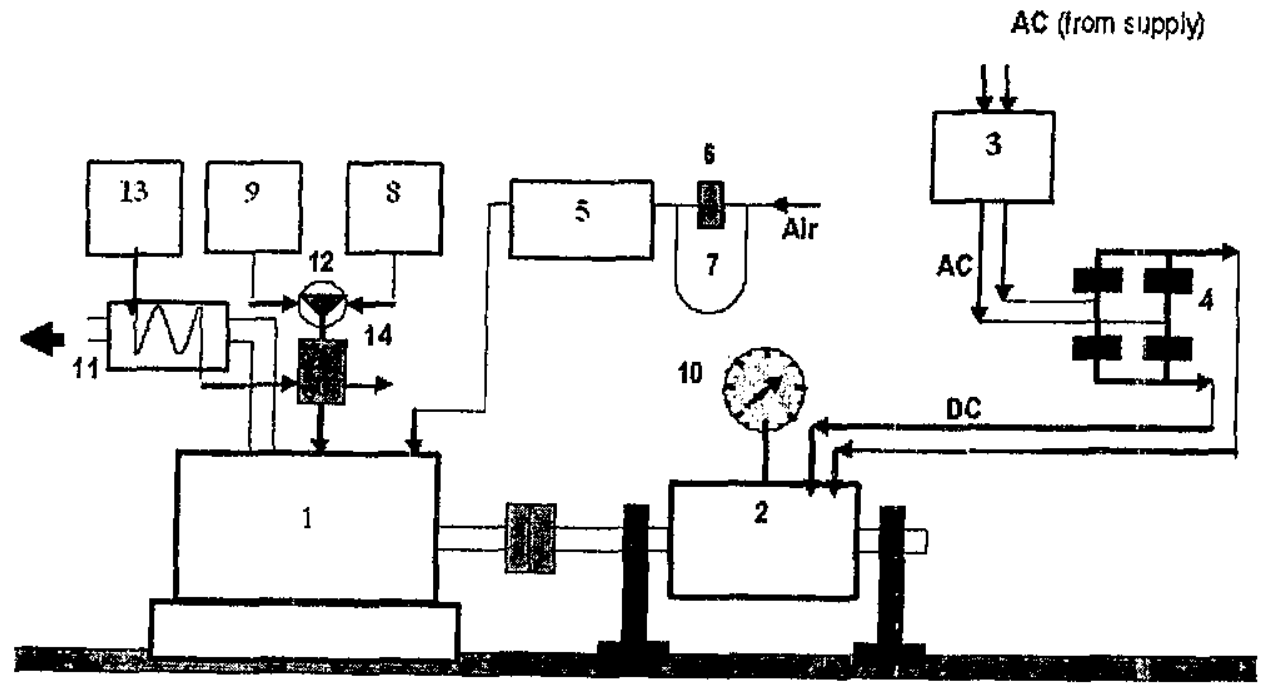

Fig. (1) Schematic diagram of the experimental setup.

(1) En gine; (2) El ectrical motor; (3) Voltage regulator, (4) Diodes; (5) Air box; (6) orifice; (7) U-tube manometer; (8) diesel fuel tank; (9) Altemative fuel tank; (10) The digital weight scale; (11) Water jacket around exhaust pipe; (12) Control valve; (13) Water tank; (14) Hot water jacket around HPP 
A. Elaskary, S. Wilson, H. Shabana and M. Farag, "Investigation of. Diesel Engines Performance Using..."

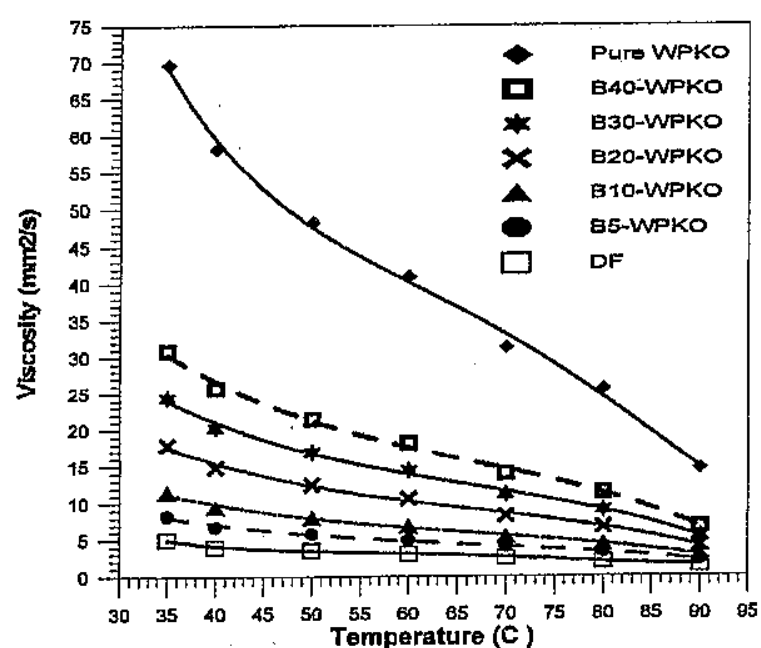

Fig.2. Effect of temperature on viscosity of WPKO and DF

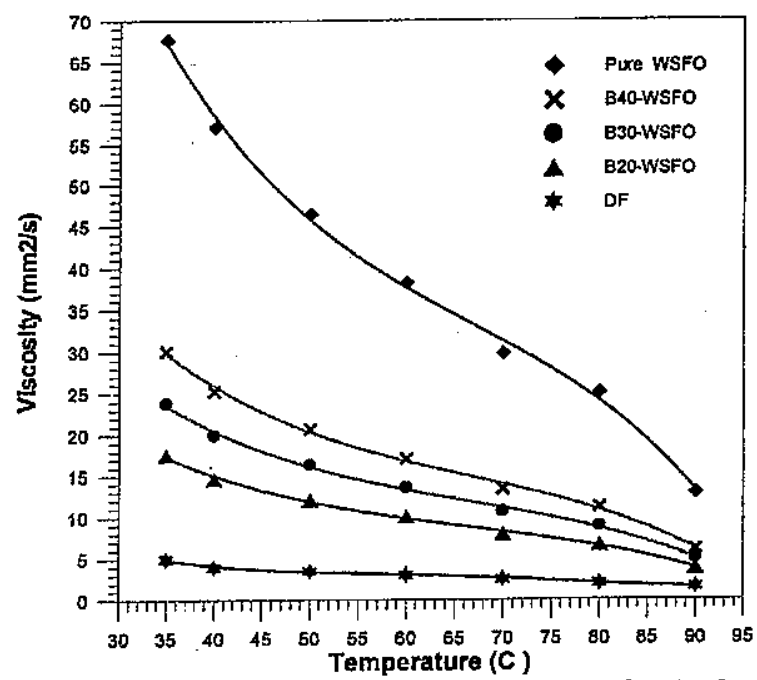

Fig.3.Effect of temperature on viscosity of WSFO and $\mathrm{DF}$

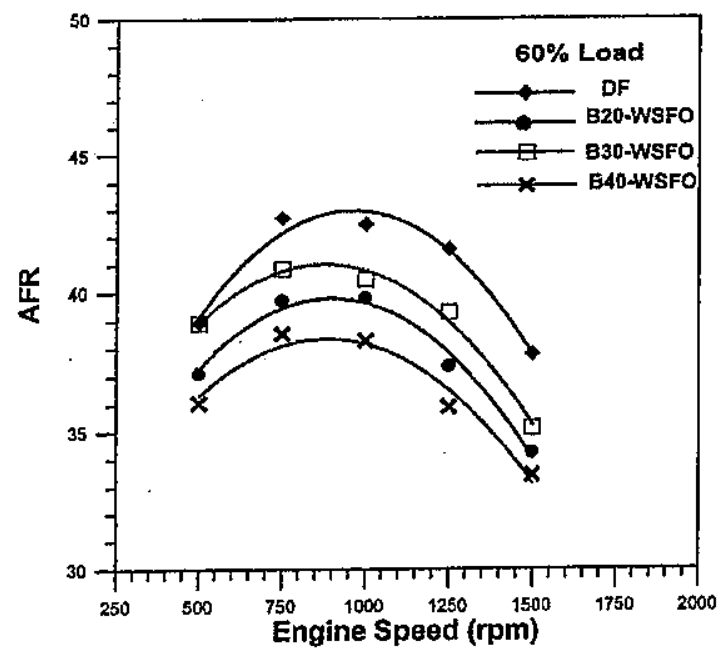

Fig.(4) AFR versus engine speed $60 \%$ load for DF and blends of DF and WSFO

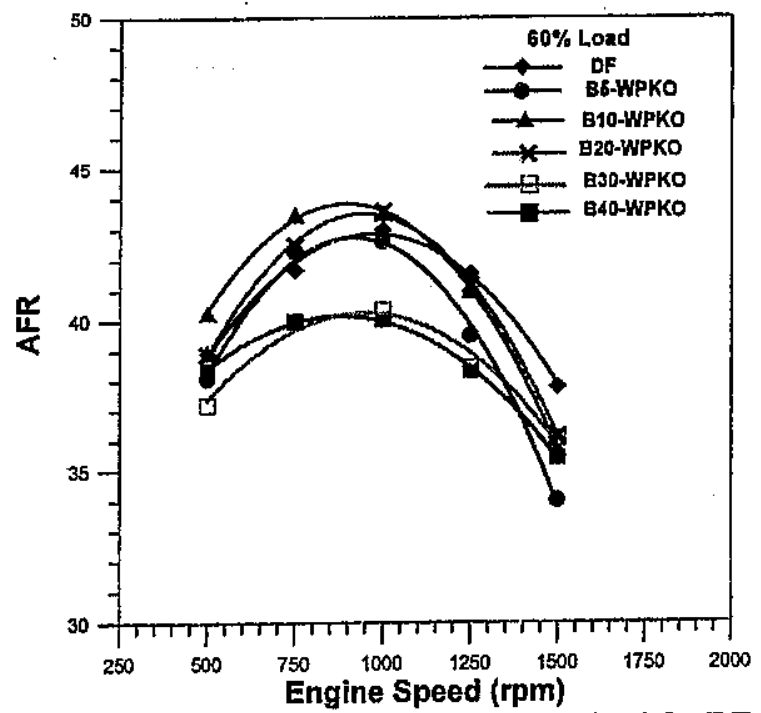

Fig.(5) AFR versus engine speed at $60 \%$ load for DF and blends of DF and WPKO

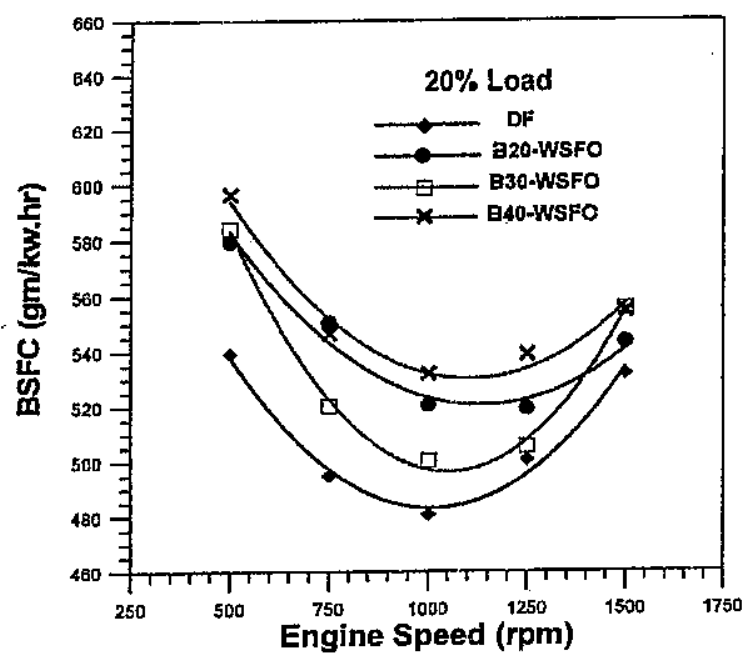

Fig.(6-a) BSFC versus engine speed at $20 \%$ load for $\mathrm{DF}$ and blends of DF \& WSFO

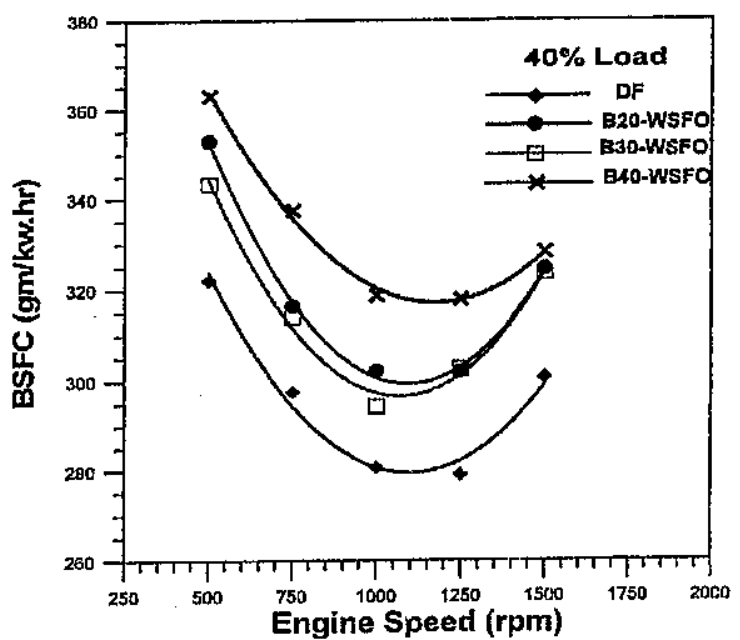

Fig.(6-b) BSFC versus engine speed at $40 \%$ load for $\mathrm{DF}$ and blends of DF \& WSFO 


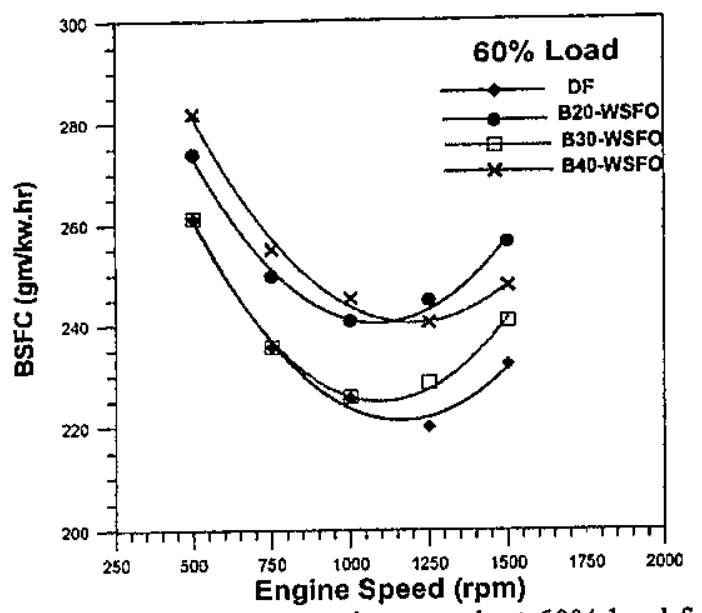

Fig.(6-c) BSFC versus engine speed at $60 \%$ load for $\mathrm{DF}$ and blends of DF \& WSFO

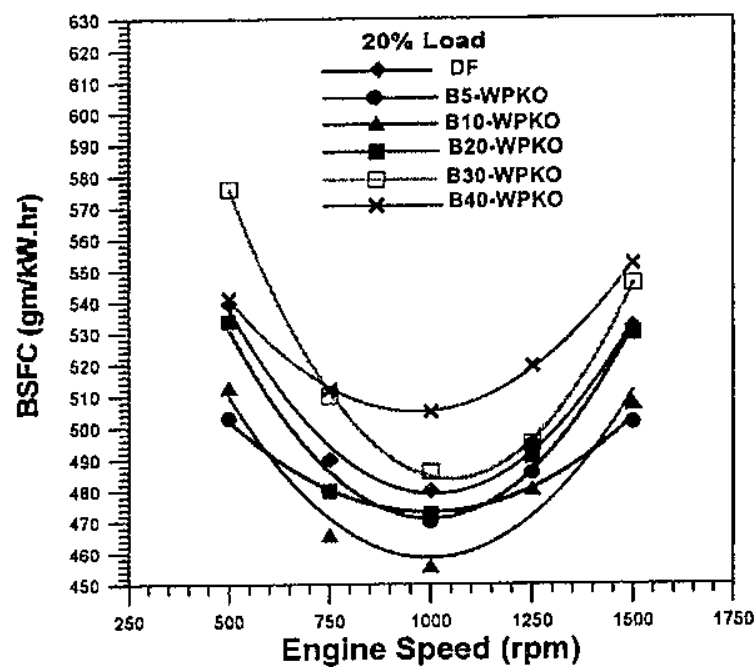

Fig.(7-a) BSFC versus engine speed at $20 \%$ load for DF and blends of DF \& WPKO

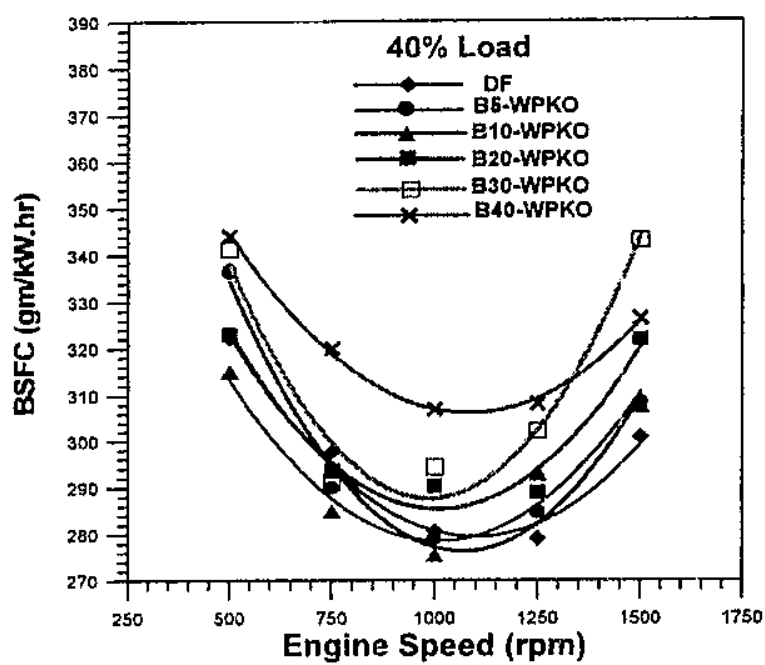

Fig.(7-b) BSFC versus engine speed at 40\% load for DF and blends of DF \& WPKO

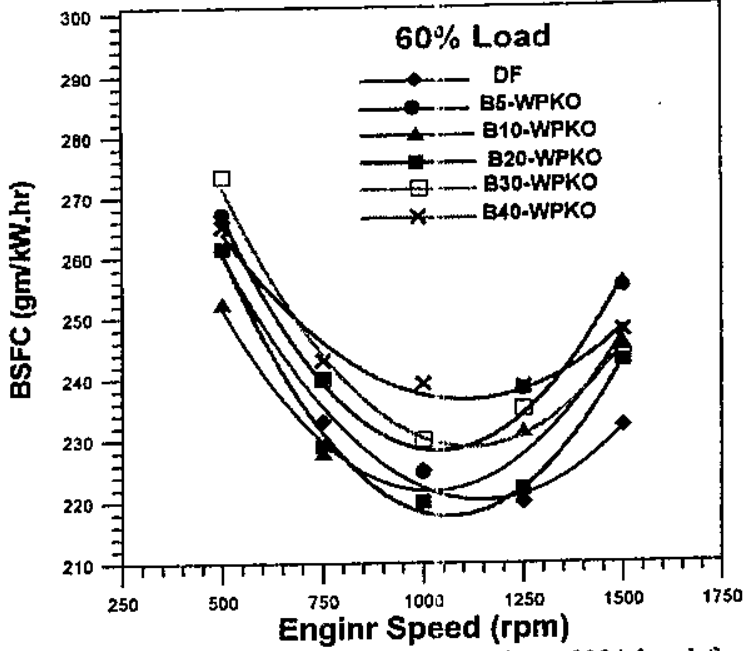

Fig.(7-c) BSFC versus engine speed at $60 \%$ load for DF and blends of DF" \& WPKO

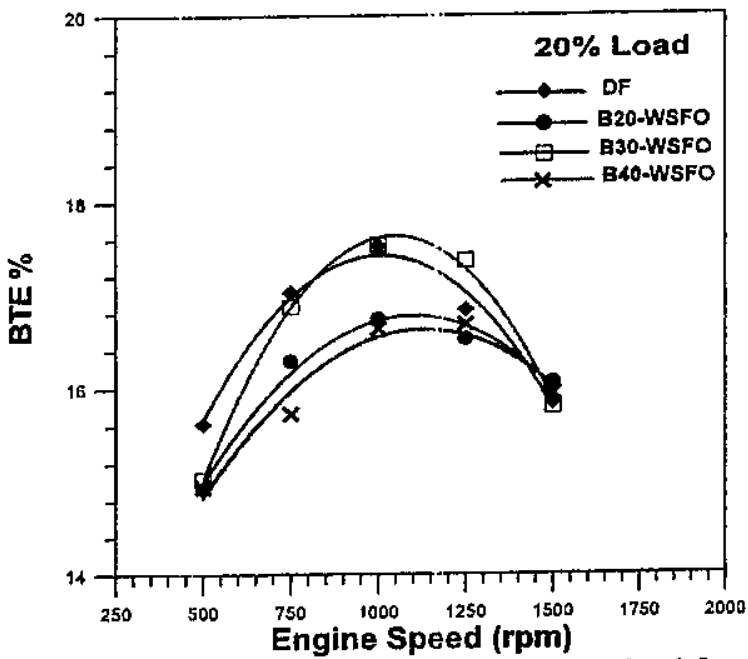

Fig.(8-a) B'T'E versus engine speed at $20 \%$ load for DF and blends of DF \& WSFO

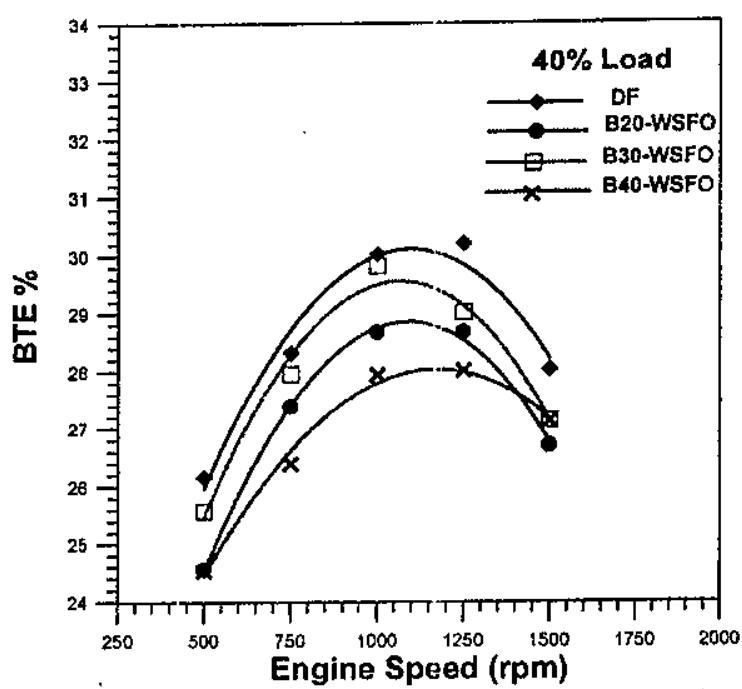

Fig.(8-b) BTE versus engine speed at $40 \%$ load for $\mathrm{DF}$ and blends of DF \& WSFO 
A. Elaskary, S. Wilson, H. Shabana and M. Farag. "Investigation of Diesel Engines Performance Using ..."

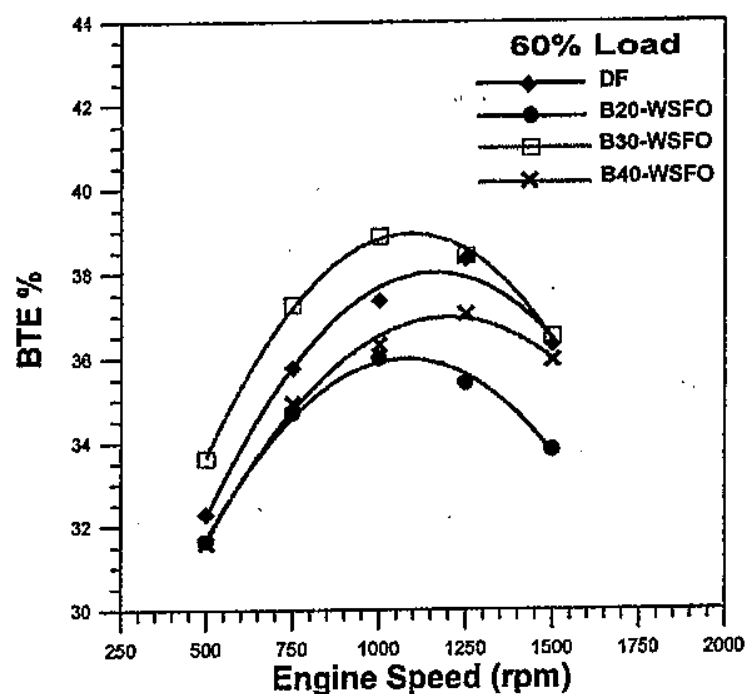

Fig.(8-c) BTE versus engine speed at $60 \%$ load

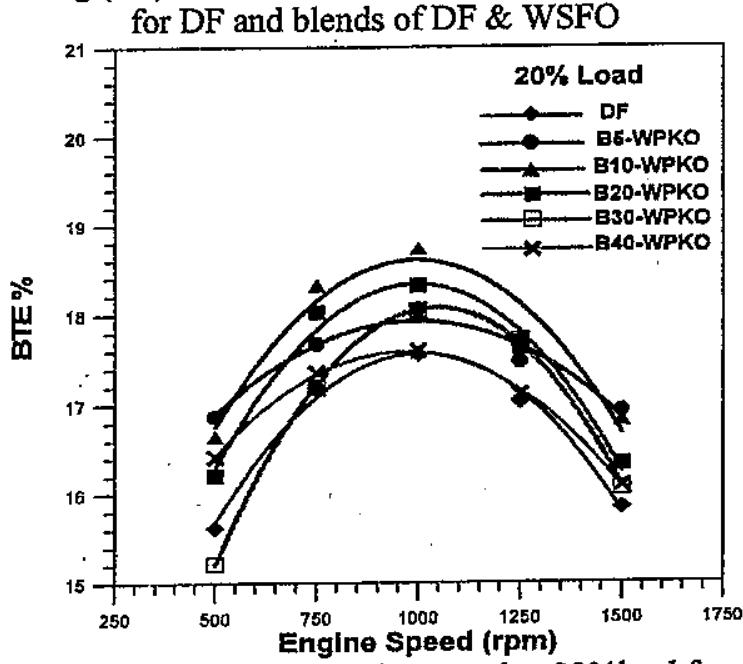

Fig.(9-a) BTE versus engine speed at $20 \%$ load for DF and blends of DF \& WPKO

Inlet cooled

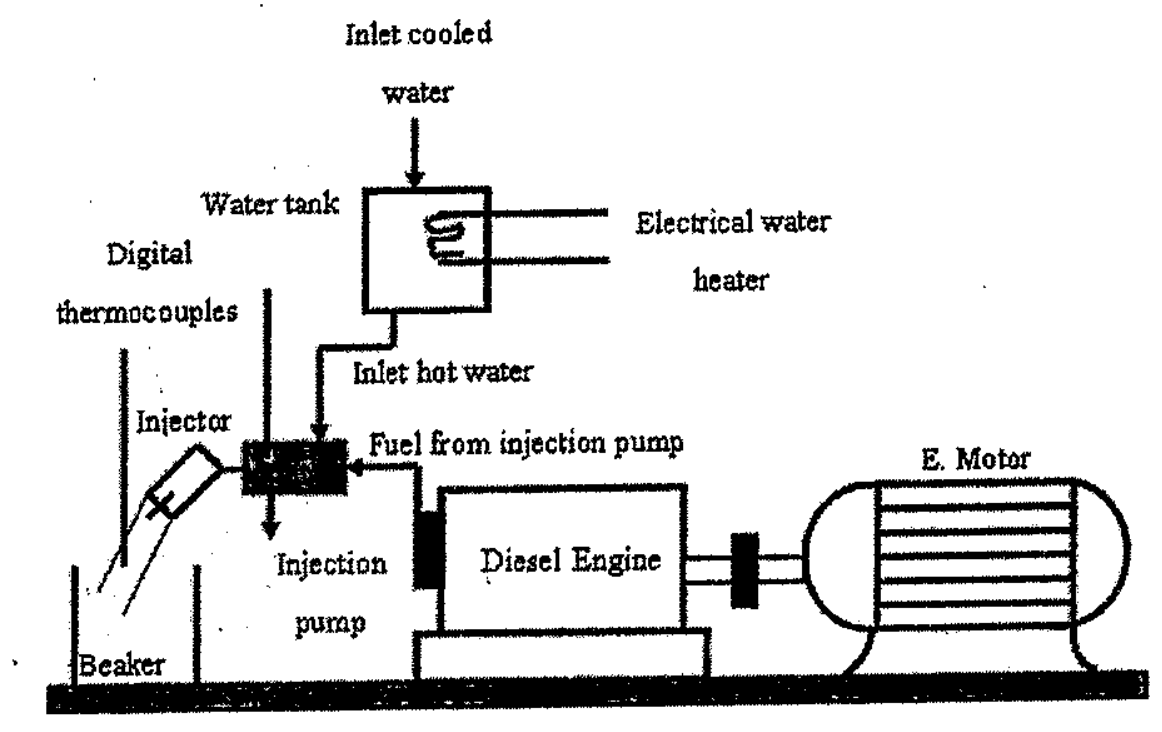

(1)H ot water jacket around HPP

Fig.(10) Schematic Diagram of the Water and Fuel Temperatures Measurement Mechanism

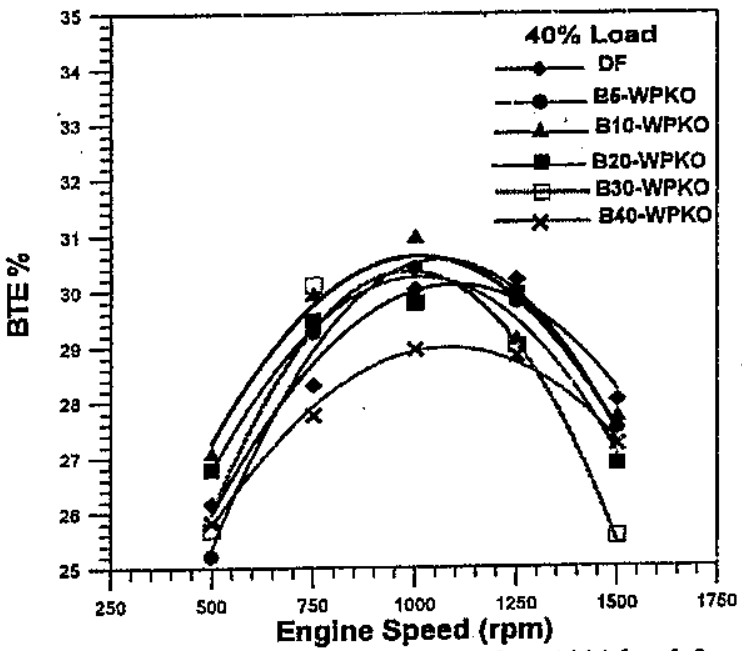

Fig.(9-b) BTE versus engine speed at $40 \%$ load for

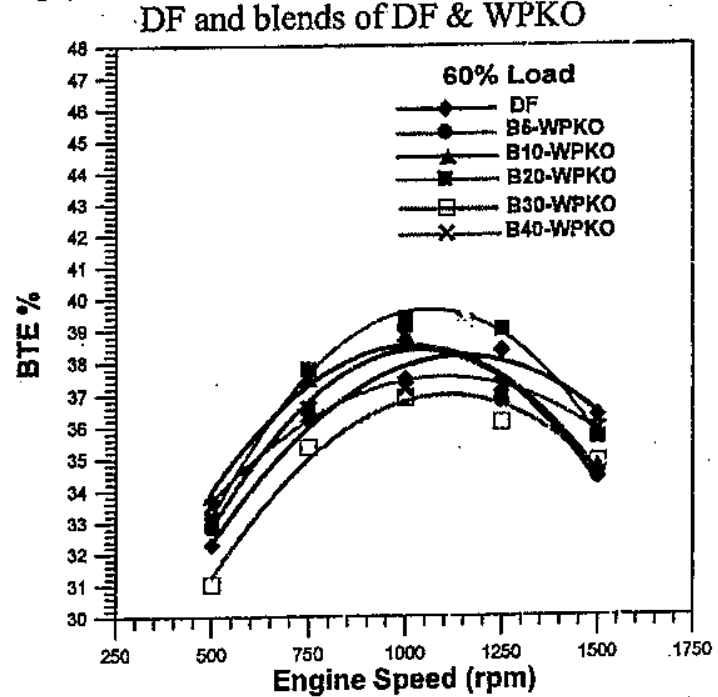

Fig.(9-c) BTE versus engine speed at $60 \%$ load for $\mathrm{DF}$ and blends of DF \& WPKO 


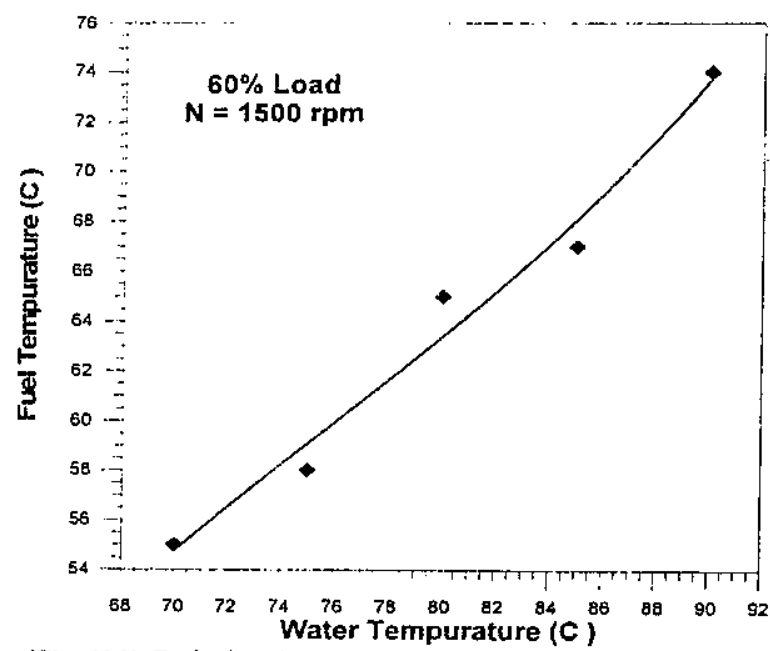

Fig.(11) Relation between Water Temperature and Fuel Temperature

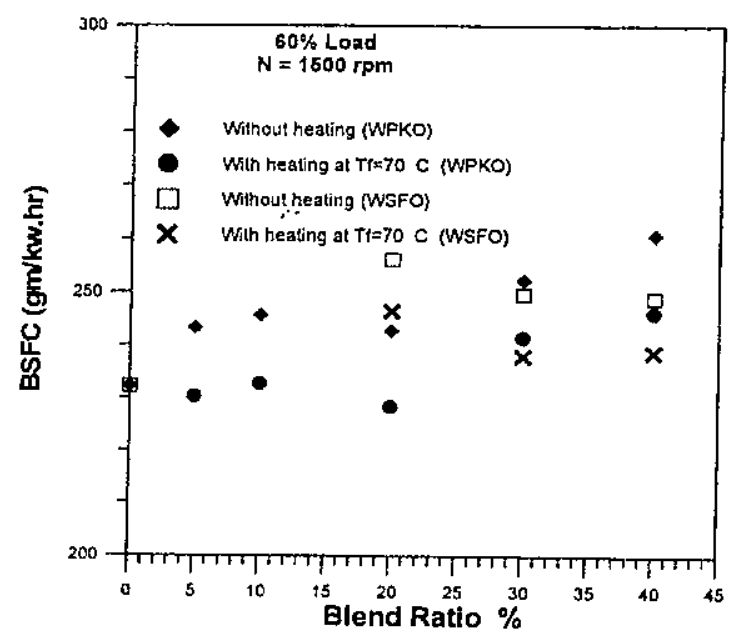

Fig. (12) Effect of blend ratio on BSFC

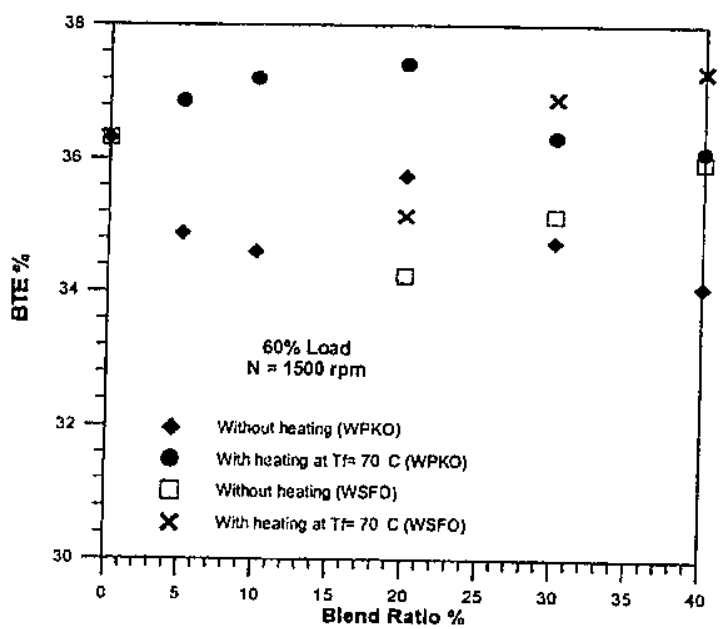

Fig. (13) Effect of blend ratio on BTE
TDC $\quad$ BDC

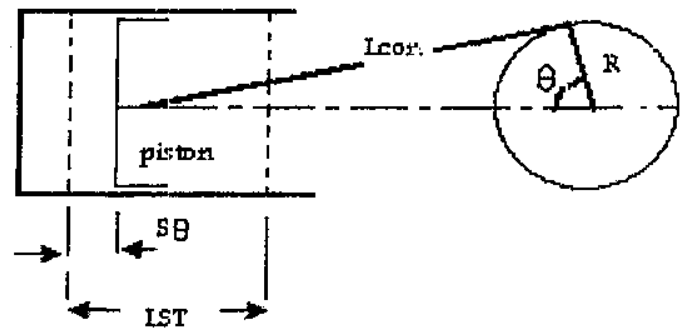

Fig (14) Crank - Slider Mechanism

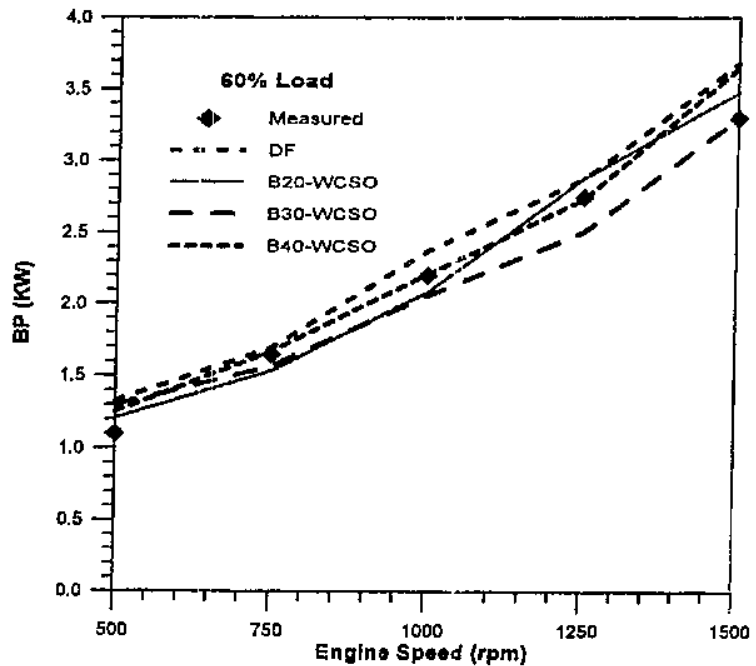

Fig. (15) Relation between BP and Engine Speed

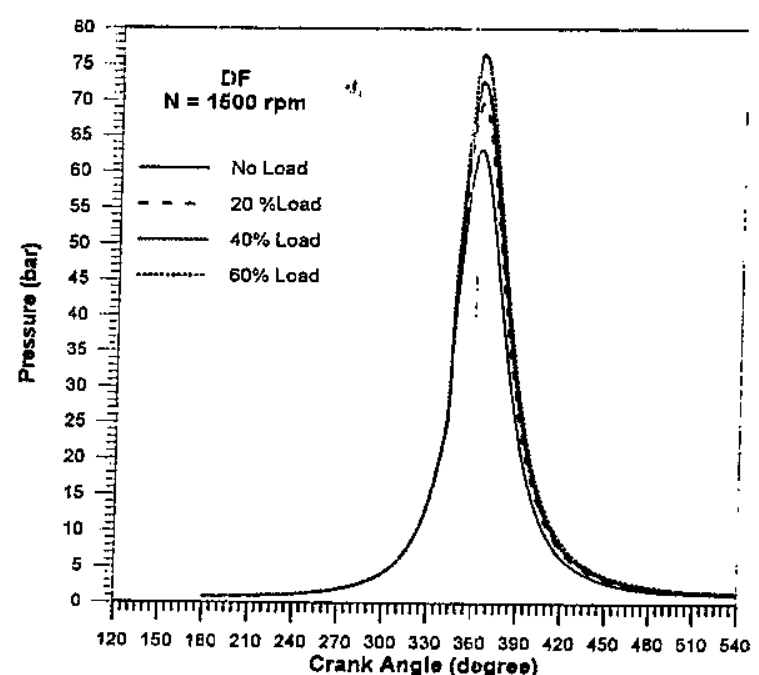

Fig.(16-a) Effect of load on Cylinder Pressure with Crank Angle Degrees 


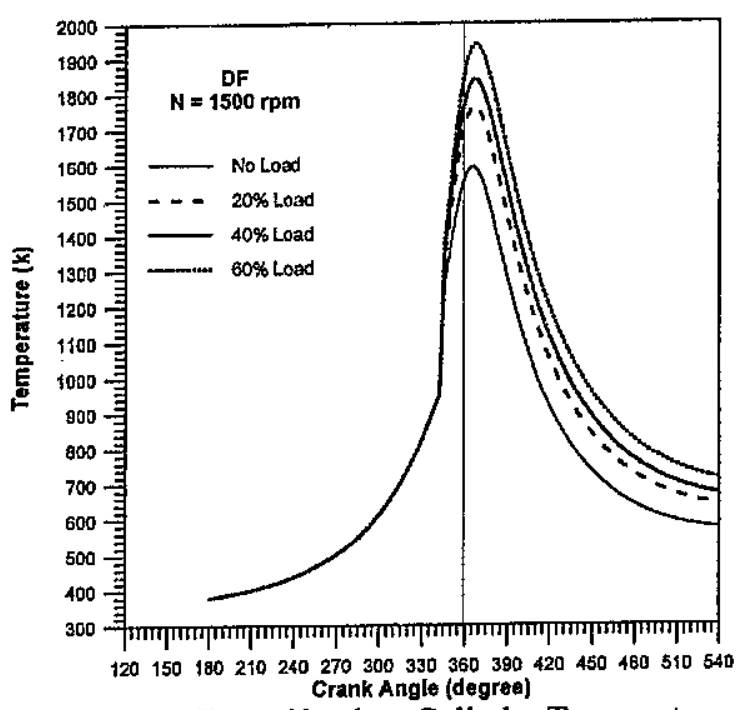

Fig.(16-b) Effect of load on Cylinder Temperature with Crank Angle Degrees

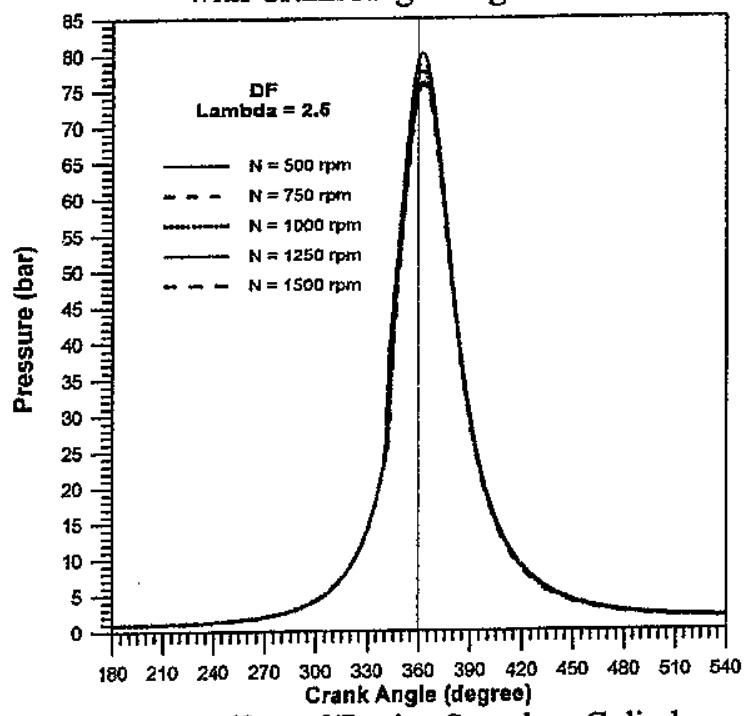

Fig. (17-a) Effect of Engine Speed on Cylinder

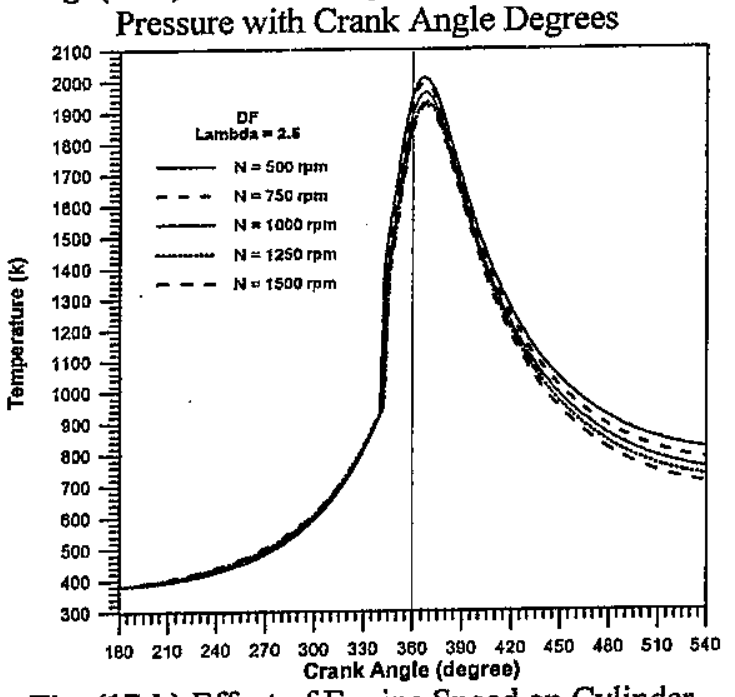

Fig. (17-b) Effect of Engine Speed on Cylinder Temperature with Crank Angle Degrees

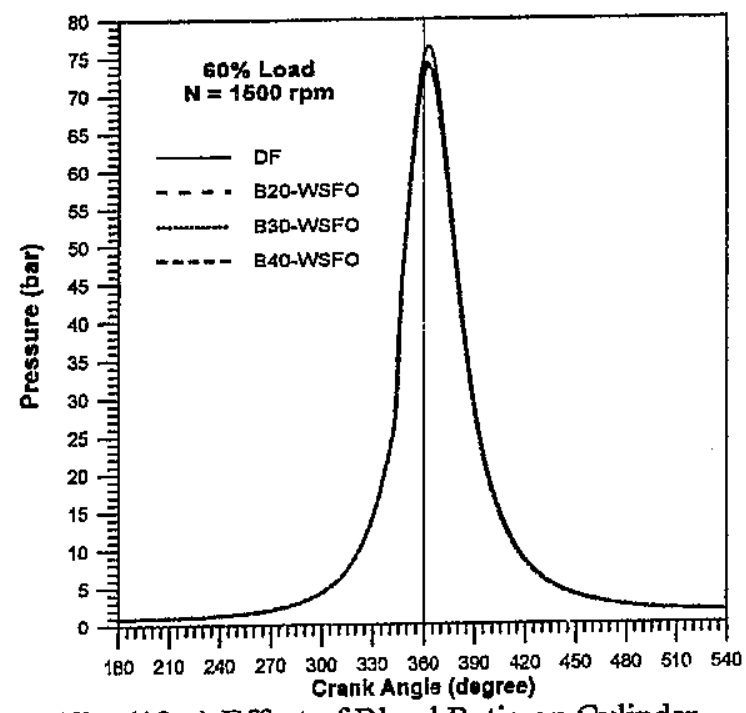

Fig. (18-a) Effect of Blend Ratio on Cylinder Pressure with Crank Angle Degree

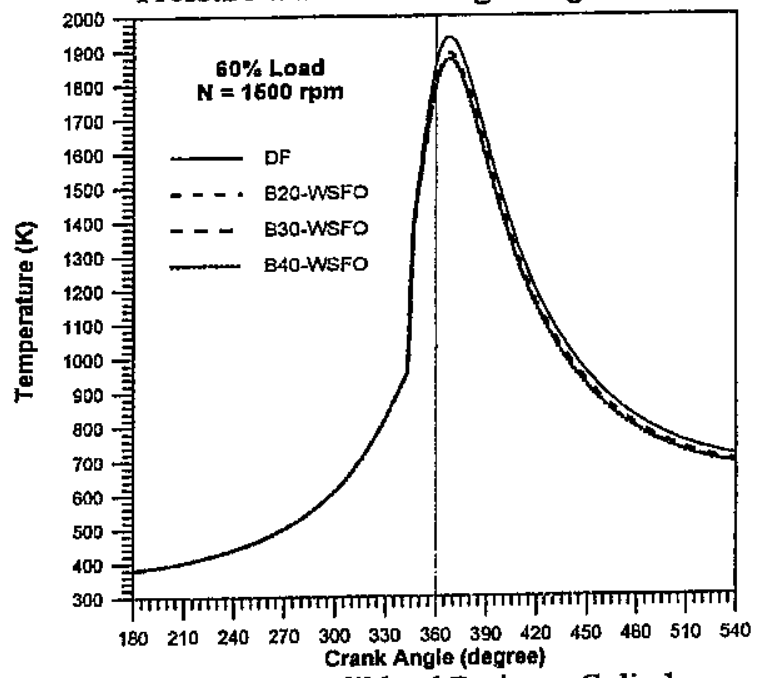

Fig. (18-b) Effect of Blend Ratio on Cylinder Temperature with Crank Angle Degree

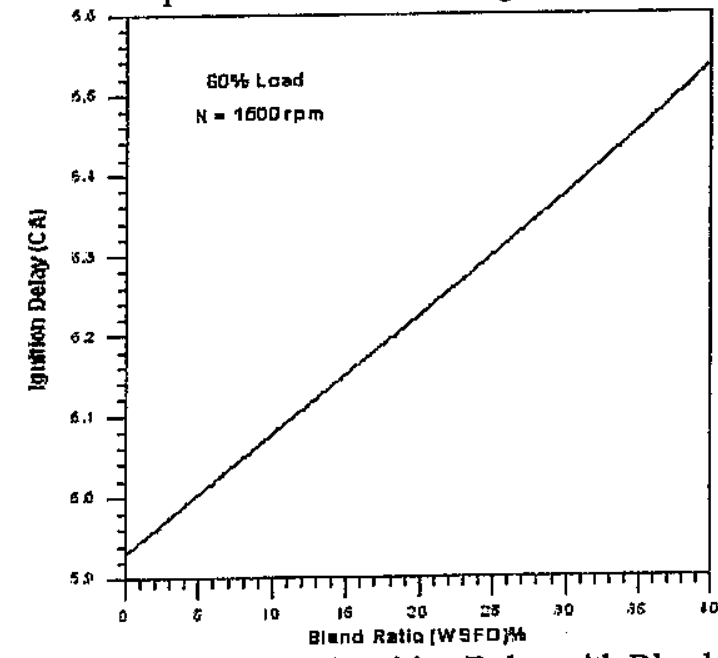

Fig. (19) Variation of Ignition Delay with Blend Ratio of WSFO 